\title{
The Construction of Builder Safety Supervision System Based on CPS
}

\author{
Wei Jin, ${ }^{1}$ Yu Liu $\mathbb{D}^{1},{ }^{1}$ Yanfeng Jin $\mathbb{D}^{1},{ }^{1}$ Mengxiao Jia, ${ }^{2}$ and Lifeng Xue ${ }^{1}$ \\ ${ }^{1}$ Shijiazhuang Posts and Telecommunications Technical College, Shijiazhuang Hebei 050021, China \\ ${ }^{2}$ The 54th Research Institute of China Electronics Technology Group Corporation, Shijiazhuang Hebei 050081, China \\ Correspondence should be addressed to Yu Liu; liuyu@cptc.cn
}

Received 15 June 2020; Revised 7 July 2020; Accepted 25 August 2020; Published 18 September 2020

Academic Editor: Wei Wang

Copyright (C) 2020 Wei Jin et al. This is an open access article distributed under the Creative Commons Attribution License, which permits unrestricted use, distribution, and reproduction in any medium, provided the original work is properly cited.

\begin{abstract}
In recent years, with the development of the economy, the building industry has developed rapidly. However, due to the frequent construction safety accidents caused by natural factors and human factors, construction safety issues have also attracted the attention of the government and all walks of life. The widespread use of the Internet has made CPS an advanced technology that adapts to new social development methods and strengthens national construction. In this paper, in order to reduce the losses caused by construction accidents, firstly, the types of safety accidents are analyzed. Secondly, on the basis of CPS technology, a safety system for building workers is constructed, which is mainly composed of four parts, which are personnel management system, risk crosswarning system, monitoring, early warning system, and remote monitoring system, combined with related supporting systems. Finally, the fuzzy evaluation method is used to evaluate the safety system. It is concluded that in the process of building safety construction, prejob training should be conducted to help workers establish safety awareness, and workers' contact with not safety areas should be minimized to reduce accidents in advance; the safety supervision system constructed in this paper will help improve the management level of building safety management and reduce the incidence and losses of accidents. The evaluation results prove the superiority and effectiveness of the system.
\end{abstract}

\section{Introduction}

For a long time, the construction industry in the world belongs to the accident-prone industry, and the security situation is very serious. The frequent occurrence of construction safety accidents not only causes heavy casualties, construction period delay, and economic loss but also brings great pain to the casualties and families, causes harm to the whole society, threatens the development of the industry and the reputation of the government, and its direct and indirect social and economic losses are very huge. The problem of construction safety has attracted wide attention from all walks of life. How to improve the safety performance of construction industry is the common focus of academia and industry.

In order to reduce the losses caused by accidents in the construction industry, both experts in relevant research fields and managers in the construction front line attach great importance to the safety supervision of builders. At present, with the birth of AR/VR technology, the construction industry will also apply AR technology to prevent accidents. Using AR technology to simulate the virtual construction site, builders only need to wear VR glasses, and they can experience the construction site firsthand and feel the possible changes of body feeling and surrounding environment before possible accidents. For example, in practical work, similar "experience" can be used to predict the danger in advance. Compared with the traditional safety training for workers, this method reduces the occurrence of accidents to a certain extent. However, it is not scientific to predict the occurrence of accidents only based on the experience of workers.

With the introduction of CPS technology, it has been widely used in many fields. For example, government work, smart campus, transportation, smart home, and even our daily communications are the embodiment of the CPS application. This paper will use the CPS technology to achieve 
safety supervision of builders, in order to reduce the occurrence of accidents and reduce the loss of personal and property caused by accidents.

CPS is a comprehensive, physical and controllable multidimensional intelligent system, which can realize real-time perception, dynamic control, and information service of complex system, which has the characteristics of safety, reliability, implementation, and efficiency [1-3]. Compared with the traditional Internet of Things system, the intelligent fire control system based on CPS can realize the intelligent processing of fire control system and meet the complex work requirements of fire monitoring and intelligent watch through the crossintegration of fire control business logic, big data, and artificial intelligence.

In the construction safety management system and major laws and regulations [4, 5], European countries and some developed countries started earlier, developed more balance, and paid more attention to the staff. To investigate the causes of construction site safety accidents, there are the following main problems: unreasonable layout of construction site, which makes different working areas have a cross section [6]; insufficient safety inspection, which makes the potential safety hazards in construction site not found and eliminated in time [7]; poor management of machinery and equipment, which cannot be repaired or replaced in time [8]; the aging of power lines has not been updated in time, which leads to the occurrence of workers' electric shock accidents [9], and the level and quality of safety protection in construction need to be improved. At the same time, due to the lack of safety awareness and self-protection awareness of builders [10], measures that cannot be strictly implemented as required lead to frequent accidents. In order to reduce the occurrence of workers' safety accidents, experts and scholars from various countries have proposed solutions, for example, the "truss" structure proposed by British scholar Mayton, which is a system that renders and infers building safety through the real-time streaming of the construction site environment. Literature [11] proposes a proximity sensing and alarming technique for heavy construction equipment operation. Liu Hongling and others focused on building safety detection and designed a large-scale building safety remote detection system based on the CPS technology. The networking of database transmission and its security information processing system are given. Considering building safety, Teizer and Cheng [12] and other people proposed an automatic approach hazard indicator to collect perceptual information about the intersection of workers and mobile devices, which is helpful to identify dangerous areas in the construction site. In urban underground business district, which is an important form of comprehensive utilization of urban underground space, Tan Zhanglu established a three-in-one safety management system of urban underground business district based on CPS to ensure its safety. In the literature, wireless sensor networks are deployed on the construction site to monitor potential hazards that workers may face.

The CPS has a wide range of applications and has applications in the field of construction worker safety supervision. With the continuous development of the economy, the development of the construction industry has been accelerated. As far as cities are concerned, the construction of residential buildings, large shopping malls, and entertainment and leisure places has brought convenience to people. However, compared with manufacturing industry, construction production has the characteristics of large amount of information, many uncertainties, and complexity. The CPS technology has a wide application prospect in the field of construction.

This paper is mainly divided into five parts. In the first part, in order to solve the loss caused by frequent accidents in the construction industry, the CPS technology is applied to the construction site, and some work done by relevant scholars and the basic concepts of the CPS are introduced. The second part introduces the technical structure of the CPS and applies it to the field monitoring management, safety management, early warning of dangerous areas, and building materials in the construction process. The third part, according to the characteristics of the construction industry, regards each construction site as a whole and constructs a construction site safety supervision system which is composed of personnel management system, risk crossearly warning system, panic and early warning system, and remote monitoring system based on the CPS technology. These four subsystems have a clear division of labor, constitute a whole, and are carried out on a construction site. In the fourth part, the fuzzy evaluation method is applied to evaluate the safety supervision system and verify the rationality of the system. The last part is a summary of this paper.

\section{Application of the CPS Technology in Building Construction}

For occupational safety and health costs, there are prevention costs and accident costs. The relationship between them is shown in Figure 1. Among them, the amount and difference of prevention cost and accident cost are affected by the change of safety level [13].

The three curves in Figure 1 show that $T$ is the total cost of occupational safety and health, $C$ is the accident cost, $P$ is the prevention cost, and the three meet $T=C+P$. It can be seen from the figure that when the accident cost and prevention cost are the value at the $M$ point, the total cost is the lowest and is the profit maximization point from the enterprise's point of view. On the left side of point $M$, the accident cost investment is relatively high and the prevention cost is relatively low. When the cost input is allocated according to it, many benefits can be brought; for example, it has a great impact on the stability of the human heart, and at the same time, it will bring corresponding benefits to the enterprise. On the right of point $M$, the increase in preventive cost input can improve the worker's work efficiency and speed up the completion of the work, so the benefit can offset the cost of the total input; that is, the increase in the total cost does not necessarily reduce the benefit. Therefore, there is a unified relationship rather than a confrontation between production efficiency and safety level [14]. Enterprises' investment in construction can bring certain economic benefits, and it is particularly important to reduce accidents. 


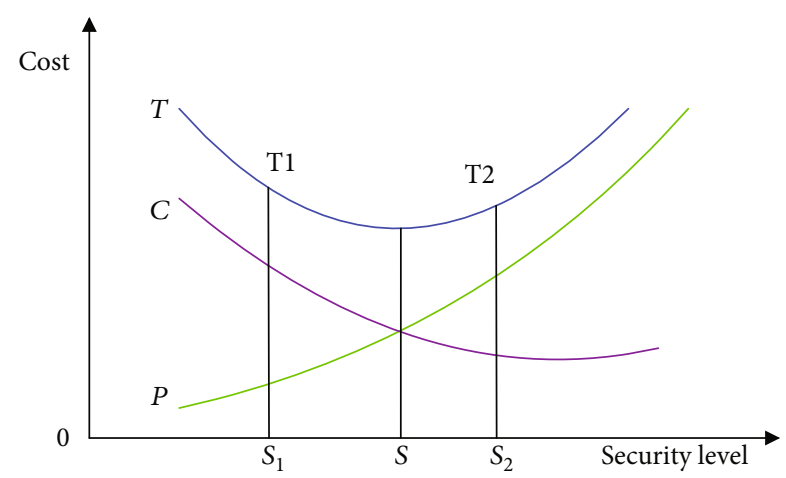

Figure 1: Occupational safety and health expense model.

The application of the CPS technology in a construction site provides better solutions to many problems. The CPS technology detects unsafe factors at the construction site through information sensing devices such as radio frequency identification (RFID), global positioning systems, gas sensors, and human behavior sensors [15]. When a dangerous situation is detected, it sends a signal to the field workers in time to let the staff make safety protection, so as to reduce the adverse effects of accidents on the construction site. The CPS technology is mainly divided into three layers [16]: the physical layer, the network layer, and the information layer, as shown in Figure 2.

The physical layer contains the hardware of CPS, such as sensors and actuators. The actuators directly or indirectly change the physical world, and the sensor samples sense the physical world.

The network layer is only responsible for the transmission of information and plays an important role in connecting the physical layer and the information layer, so it is regarded as an independent layer. The network layer includes various communication protocols and devices of the network, such as hubs, switches, and routers.

The information layer is responsible for the processing of information, including the calculation, identification, pattern matching and other processing of the information collected by the physical layer, the preservation of all kinds of information in the system, the management and configuration of the system, the making of decisions and orders based on perception, and the scheduling of tasks and resources.

\subsection{On the Supervision and Management of Construction} Site. In the safety management process of the construction site, the application of the CPS technology can not only effectively supervise and manage the things and construction operations on the construction site but also actively respond to and warn the unexpected safety accidents on the construction site. The CPS technology has the advantages of high sensitivity, small space occupied for laying, and resistance to electromagnetic interference. It is suitable for application in the field of construction safety monitoring. In addition, the CPS technology can also effectively monitor the operation of high-rise buildings, bridges, roads, tunnels, water conservancy, and dam projects and can make timely response when danger occurs. In order to detect and monitor the impact force, shape control, and vibration damping in the construction project, the perceptual devices belonging to the perceptual layer in the CPS technology are pasted in the wall of the monitored area and some movable devices and laid in the middle of the engineering structure. Through the analysis of the data returned by the sensors, the defects and deficiencies existing in the construction process are corrected in time.

2.2. Safety Management in the Construction Site. In the construction industry, safety accidents may occur at any time. Therefore, the safety hazards at the construction site have become the most important aspect of the daily monitoring and supervision work of the construction party and contractor. The application of the CPS technology can give early warning to the occurrence of safety accidents in the construction site. The technology of CPS is used to monitor the risk factors at the construction site, and the RFID marking is put on the protective shed near the entrance or exit or on the protective equipment at both ends of the elevator wellhead. In addition, corresponding commands such as tag number, hazard protection level, hazard parameter judgment threshold, and alarm information are input into the radio frequency identification chip, which should be consistent with the location and requirements of the building. Accordingly, the management of safety factors in the construction site is realized.

In the construction industry, it is difficult to monitor the safety of workers working at high altitude. At this time, the same RFID sign can be installed on the safety configuration of the safety helmet and seat belt of the high-altitude workers. Then, according to the building information model, the position of high-altitude workers can be accurately positioned. In the event of a dangerous accident, it is convenient for the operator to be found by the site safety management personnel in the shortest time. The management personnel take safety measures quickly to avoid the accident as far as possible.

2.3. Early Warning of Dangerous Areas. As an industry with high incidence of dangerous accidents, the environment of the construction site is usually relatively complex and scattered. In addition, most of the construction site workers are less educated. Workers have insufficient knowledge of the hazards and are prone to enter relatively dangerous work areas, posing a great threat to the safety of construction workers. When construction workers overlap with dangerous areas, it means that there are constructors entering dangerous areas. At this time, the CPS technology will immediately issue a danger warning to warm constructors to leave dangerous areas immediately.

2.4. Safety Management of Building Materials. High-quality building materials are an important guarantee for the quality of construction projects. Only when the building materials are guaranteed, the quality of building construction can tend to a good direction. Therefore, the safety management of building materials is also very important in the entire construction project. In terms of quality control of building materials, the CPS technology can identify building materials 


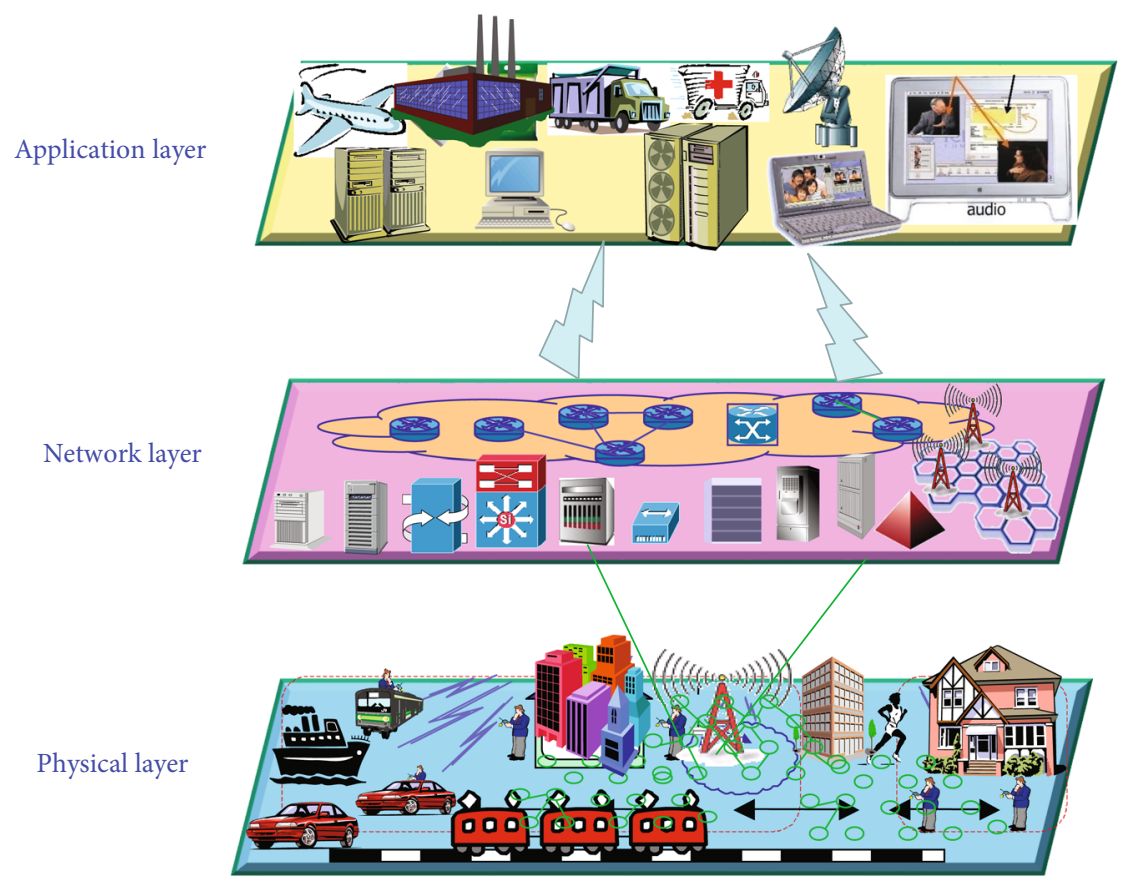

FIgURE 2: The structure of CPS.

by barcode sweeping, so that it is not necessary to open the outer packaging or protective layer of building materials. The CPS technology can easily identify the encoding of building material microelectronic chips by scanned code. Workers can use the CPS technology to control the quality of building materials. At the same time, Internet technology also helps to achieve transparent quality monitoring and management of building materials, which facilitates staff to grasp building materials and construction information at any time.

In short, as an emerging industry in the era, the CPS technology has been increasingly applied in the development of all walks of life. The CPS technology can play a great role in the construction safety management of the building industry. The application of the CPS technology in the construction site can help to realize the safety management of the construction site, protect the property and life safety of personnel on the construction site, and provide guarantee for the safe production of the construction industry.

\section{Construction Safety System Based on CPS}

This paper establishes a safety supervision system based on CPS, which is composed of personnel management system, risk crossearly warning system, alarm and early warning system, and remote monitoring system. Personnel management system is the foundation, including all the management objects. Risk crossprediction system is the center and the most important functional module. The alarm and early warning system is an information output module, which undertakes the function of information release. The remote monitoring system is the eye of the system, which pays attention to the changes of the system in real time. The four subsystems cooperate with each other and work together.
The construction safety system should follow certain principles. In the process of construction safety management, not a technology is suitable for a certain operation, but the integration of many technologies to realize the comprehensive management of people, objects, and computers in construction, so as to realize the purpose of early warning of danger and reduce accident risk. In the construction process, the selectivity faced by the staff should be minimized, that is, the uniqueness of the system implementation. The construction site is a dynamic process of continuous change, so the parameters of the equipment collected by sensors in the management system are constantly updated, which requires the continuous operation of the safety system. According to the principles of building construction safety system and the three characteristics of the CPS, perception of objects, information transmission, intelligent processing, and the CPS technology can be applied to it. The perceptual layer of the CPS perceives some parameters of construction facilities set in advance and transmits these information to the network layer. The network layer analyzes the returned information and makes corresponding judgments according to different dangerous situations by setting threshold. The application layer makes certain decisions based on the judgments made by the network layer, dangerous early warning, accident handling, and so on.

Safety management in the construction industry has the characteristics of high mobility of construction team, complex composition of staff, and staff intensive. The results of the survey of construction workers are shown in Figure 3, which are the age structure of construction workers, the professional level of construction workers, and their working years.

Through the analysis of the survey results, the construction workers have a weak understanding of building 

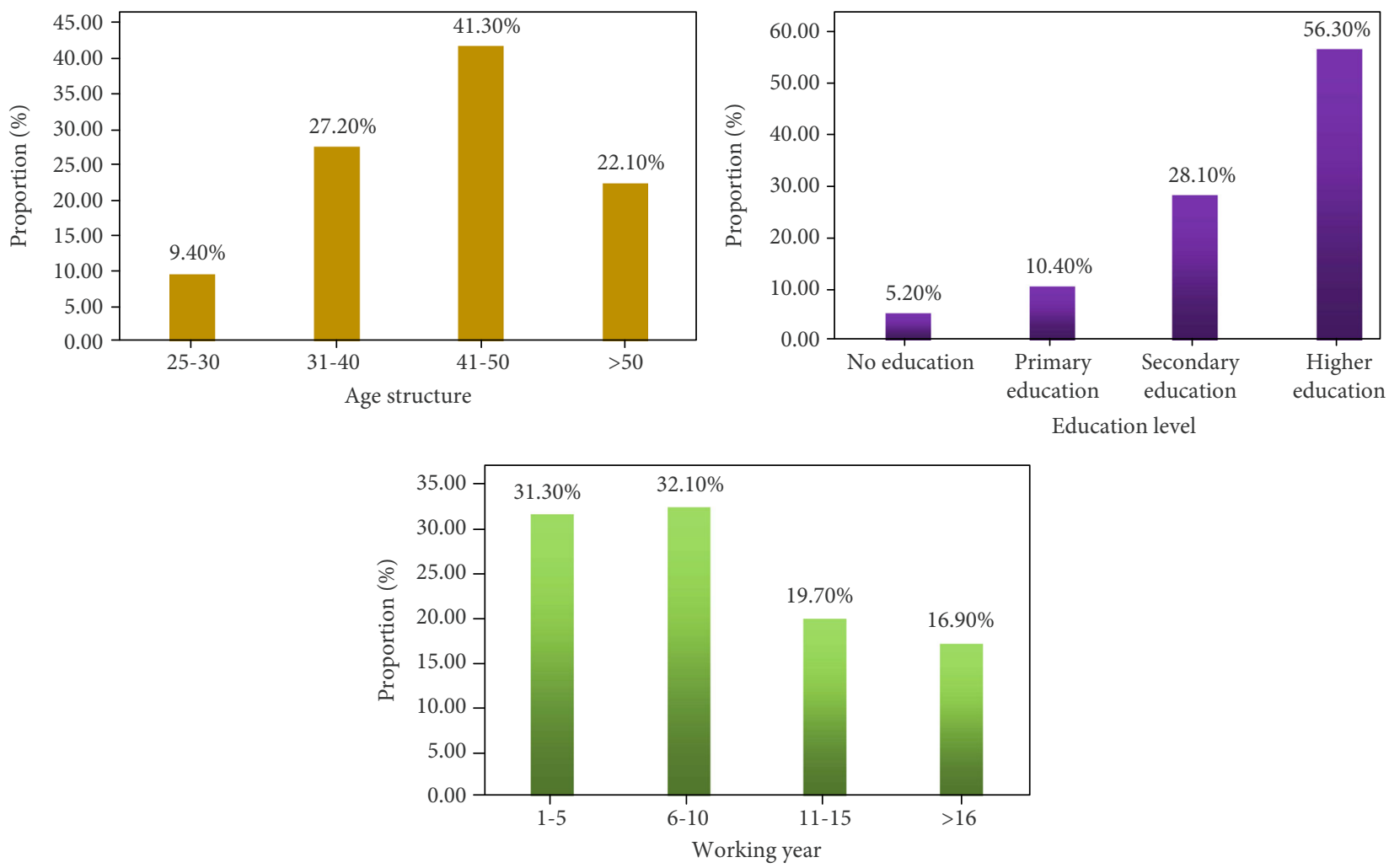

FIGURE 3: Survey results of construction workers.

expertise. Therefore, it is necessary to continuously train the construction workers' expertise to improve builders' awareness of dangers and to make timely and accurate respond when the danger occurs. However, the supervision of construction safety is not enough to improve the quality of workers. Therefore, it is necessary to build a safety supervision system on the basis of the CPS, consisting of personnel management system, risk crosswarning system, alarm and early warning system, and remote monitoring system.

3.1. Personal Management System. In the construction process, people are an important part, and the disorderly activities of workers have become one of the important factors inducing safety accidents. Workers have their own specific working areas, and the operation happens occasionally when someone enters a nonown area. Therefore, real-time supervision of workers is needed to avoid some accidents. Here, the personnel management system is set up to input the fingerprints of each staff member. Workers brush their fingerprints into the work and life fields. For those who do not belong to a certain range, because their fingerprints are not in the system of the work area, they cannot enter the work area. In this way, only the trained workers can enter the corresponding working area, which greatly reduces the accidents caused by the inexperience of the workers in a certain aspect. Based on this, a personal activity control system is constructed, and its structure is shown in Figure 4.

3.2. Risk Crosswarning System. The system uses the trajectory intersection theory, which considers that accidents are prone to occur when there is an overlap of time and space between an unsafe behavior of staff members and the unsafe state of a certain equipment in the construction site. For example, there will be large trucks loaded with raw materials in and out of the building construction environment. Because of the complex environment and dense personnel, there will be blind areas in the operation of trucks for drivers. At this time, if the staff, who are working in the blind area, do not pay attention to the approach of trucks, there is no time to avoid the accident.

Risk crosswarning system is used to make staff aware of the danger and take timely measures to avoid accidents. The system uses the function of information transmission and reading between the RFID reader and the electronic tag [17]. It attaches the electronic tag to the staff at the construction site and installs the dangerous reader in each device. The dangerous areas set by different devices are different. When a worker enters a dangerous area, the reader receives a signal from the electronic reactor worn by the worker and sends out a dangerous warning message to remind the worker to leave the area as soon as possible. This situation is reflected in the management center of the security department, showing the situation of crossrisk.

3.3. Monitoring and Early Warning System. The monitoring and early warning system mainly arranges wireless sensors for real-time monitoring of key positions in the construction site. The monitored data are transmitted to the integrated information processing center through the wireless sensor network to realize remote monitoring. Once the monitored 


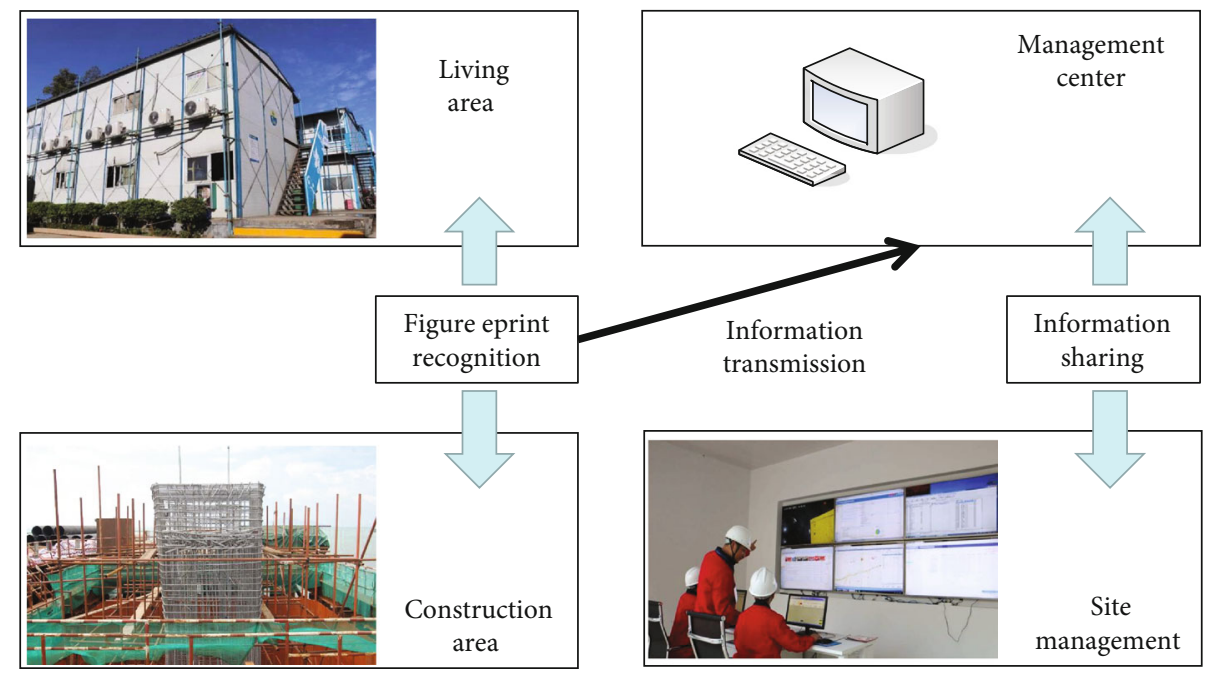

FIgURe 4: Personal activity control system.

data exceeds the threshold set by the system, the early warning system sends out dangerous warning signals to remind the construction site staff to take immediate measures and avoid accidents. Figure 5 is a schematic diagram of the monitoring and early warning system.

Every year, in the accidents caused by construction, the falling objects and collapses at high places account for a large proportion. Therefore, these two items become the focus of monitoring. The main monitoring objects are tower crane, scaffolding, formwork engineering, structure, earth and rock, collapse of piles, and so on. Each monitoring object has its corresponding monitoring content, such as the tower crane, which mainly observes the displacement of the tower seat, the degree of inclination, and the stress of the tower body. The data obtained from these monitoring objects are displayed in real time on the terminal in the form of text and graphics and are usually reflected to users in the form of curves, pies, histograms, and other intuitive forms. In this paper, the data of settlement observation of the main building during the construction of an office building are analyzed to determine whether the building is safe or not. According to the engineering practice, the datum points and settlement points are laid out for the office building. Figure 6 is the plan layout for setting settlement points. The black dots represent the location of the settlement induction device, with a total of 19 monitoring points.

Table 1 is the data attributes to be recorded at each monitoring point. This paper only shows the data records of some monitoring points on a certain day.

During the monitoring period, P5 monitoring point is selected and its broken line diagram deformation of deformation amount and the deformation after denoising treatment, as well as the residual diagram before and after processing, are displayed on the screen of the monitoring center, so that the staff of the monitoring center can more intuitively judge whether the building is dangerous enough, as shown in Figures 7 and 8 .

Through the observation of Figures 7 and 8 , the staff can judge whether the settlement of the building will affect the safety of the building, and if it exceeds the safety limit, the staff can immediately start the danger warning.

3.4. Remote Monitoring System. Remote monitoring system is based on camera technology and image recognition technology, through the installation of camera equipment in the construction area to achieve the supervision of the operation process, construction area monitoring, security hazard detection, and other functions and to improve the efficiency of safety supervision. Among them, the supervision of the operation process mainly includes whether the workers wear safety protection devices according to the requirements, whether there is an operation that violates the construction process, and whether the worker is not concentrated in the operation process. The supervision of the hidden safety hazards removes the faults and hazards from the real-time inspection of the equipment. The safety status monitoring is used to check the situation in time when there is a danger in the construction site, and the accident scene can be controlled remotely to reduce the safety risk. The operation process of the system focuses on monitoring the work process and eliminating the hidden safety hazards in the construction site.

The four systems in the safety management system of the construction site based on the CPS technology are mutually reinforcing, and their functions are overlapping. The personnel management system guarantees the orderliness of the construction area and avoids the illegal operation of nonoperators. The risk crosswarning system plays the role of dangerous warning and avoids the injury accidents caused by unconsciousness. The monitoring and early warning system is mainly aimed at the subprojects which are more dangerous in the construction process, The monitoring and early warning of the whole time can help the management personnel to find hidden dangers of safety accidents in time and take measures in advance to avoid casualties. The remote monitoring system can not only change the current situation of safety supervision and inspection in the operation process but also help 


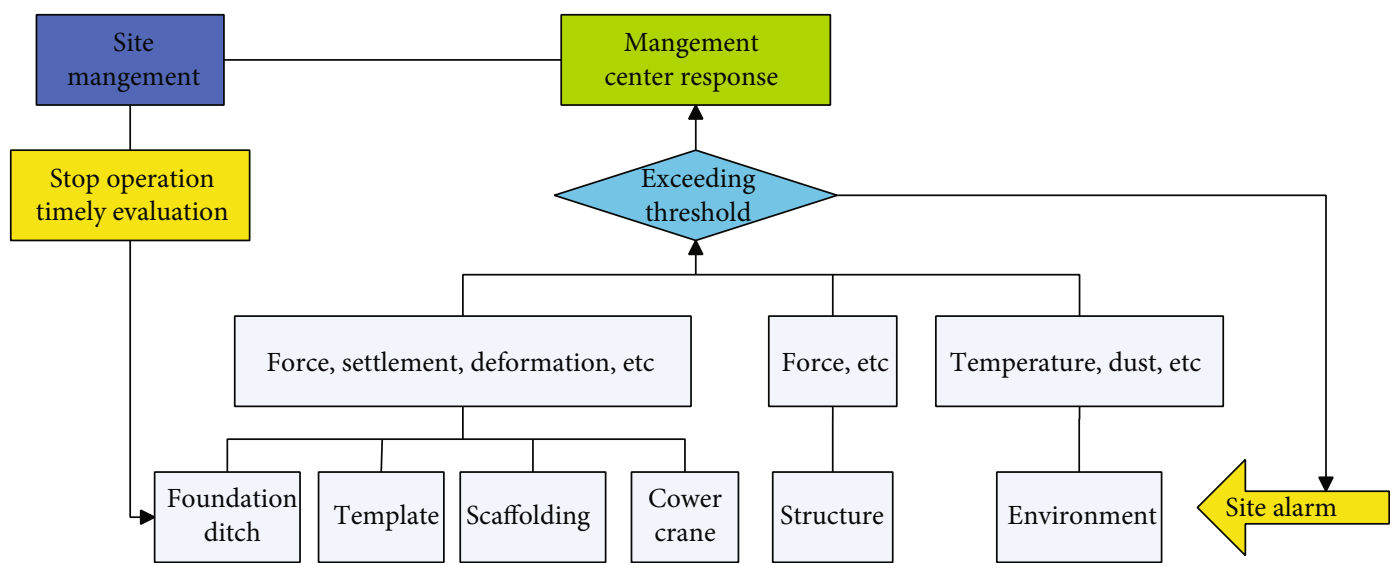

Figure 5: Schematic diagram of monitoring and early warning system.

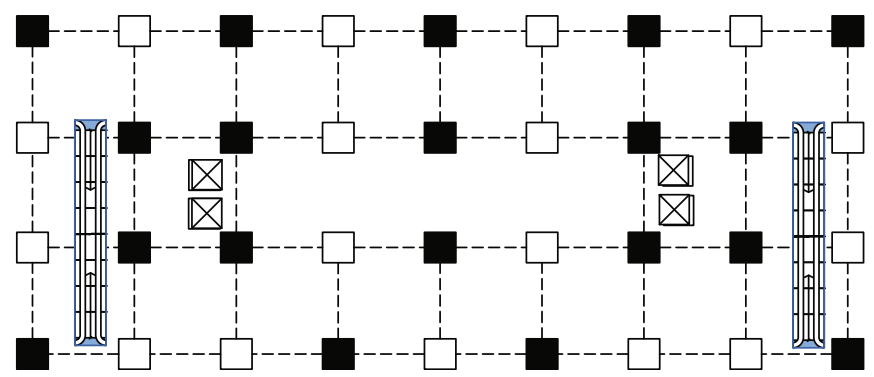

Figure 6: Plane layout of settlement observation points.

TABLE 1: Building settlement monitoring data.

\begin{tabular}{lccccc}
\hline $\begin{array}{l}\text { An office building-surface settlement monitoring daily report } \\
\text { Survey point } \\
\text { number }\end{array}$ & $\begin{array}{c}\text { Initial measurement } \\
(\mathrm{m})\end{array}$ & $\begin{array}{c}\text { Last measurement } \\
(\mathrm{m})\end{array}$ & $\begin{array}{c}\text { This measurement } \\
(\mathrm{m})\end{array}$ & $\begin{array}{c}\text { Deformation } \\
(\mathrm{mm})\end{array}$ & $\begin{array}{c}\text { Deformation rate } \\
(\mathrm{mm} / \mathrm{d})\end{array}$ \\
\hline P1 & 67.14231 & 67.14286 & 67.14247 & -0.39 & -0.39 \\
P2 & 67.13701 & 67.1377 & 67.1373 & -0.43 & -0.43 \\
P3 & 67.04162 & 67.04234 & 67.04153 & -0.81 & -0.81 \\
P4 & 67.00955 & 67.01019 & 67.00876 & -1.43 & -1.43 \\
P5 & 67.00615 & 67.00964 & 67.00538 & -1.56 & -1.56 \\
P6 & 67.05787 & 67.05851 & 67.05703 & -1.48 & -1.48 \\
\hline
\end{tabular}

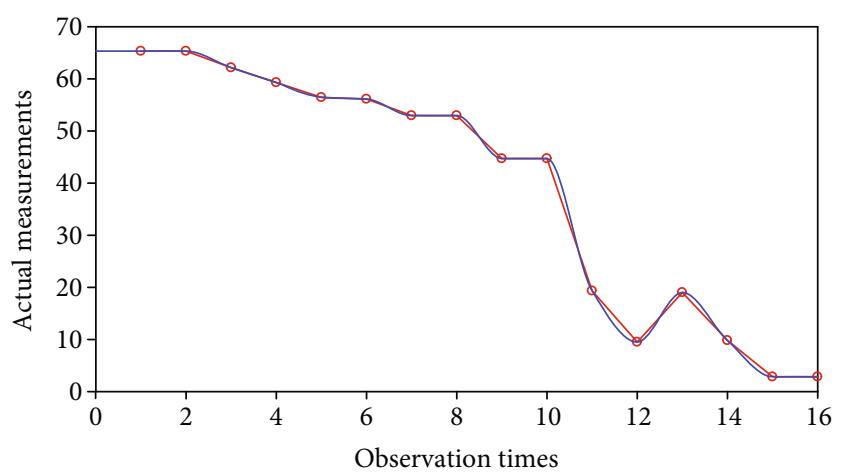

- Primary Data

- Denoise Data

FIgURE 7: P5 monitoring raw data and denoising data. managers to control the construction area as a whole. The four systems perform their respective functions and complement each other to jointly achieve the safety management objectives in the construction process.

In addition to technically avoiding accidents, workers are required to be trained before the job. The management personnel conduct regular inspections and real-time monitoring of the equipment in strict accordance with the requirements, conduct standardized management according to the system requirements, and strictly restrict unsafe behavior. Safety protection hardware on site is also one of the important factors to reduce accident injury. When the danger occurs, the emergency system will be launched to evacuate the staff on site in time and carry out emergency rescue quickly so as to reduce the damage caused by the accident. 


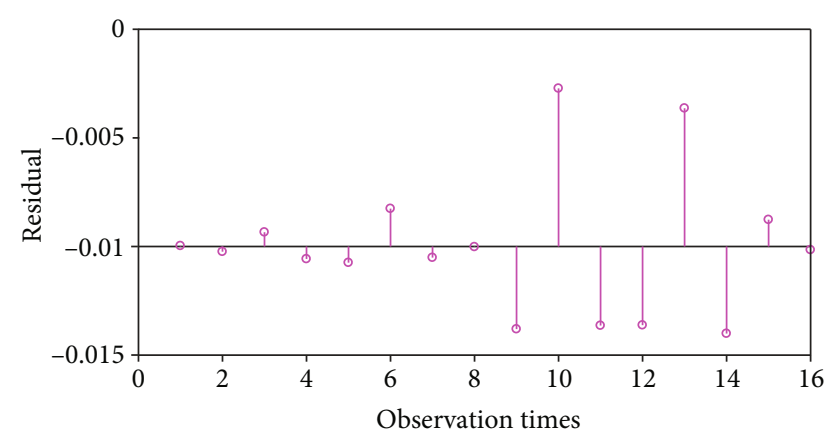

Figure 8: Residual between original data and denoised data of the P5 monitoring point.

\section{System Evaluation}

The building safety management system based on the CPS system is aimed at predicting engineering risks through effective management measures, preventing accidents, and reducing the loss of life and property caused by accidents. Therefore, the performance of the system is closely related to the loss caused by accidents on the construction site. Therefore, this paper examines the performance of the building safety supervision system based on the CPS.

In the process of construction, danger and safety are relative, and there is no clear boundary. Therefore, this paper uses the fuzzy evaluation method [18] to evaluate the system. The basic steps are as follows [19-24]:

Firstly, the evaluation grade of system safety is established, which is safety, safer, general, severe, and dangerous. The evaluation result is determined in a certain interval. The setting of the score is shown in Table 2.

For convenience of calculation, grade coefficients are set to integers.

Secondly, the weights are calculated. The comparison criteria are based on the Saaty scale method [25], which is shown in Table 3.

According to Table 3, the two pairs are compared between two layers, and the scale values are calculated, and the corresponding judgment matrix is calculated, as shown in

$$
A=\left[\begin{array}{ccc}
a_{11} & \cdots & a_{1 n} \\
\vdots & \ddots & \vdots \\
a_{n 1} & \cdots & a_{n n}
\end{array}\right] .
$$

Calculate the weight according to formula (2):

$$
\mathrm{AW}=\lambda_{\max } \mathrm{W}
$$

Among them $\lambda_{\max }$ is the maximum eigenvalue of matrix $\mathrm{A}$, and $\mathrm{W}$ is the eigenvector corresponding to the maximum eigenvalue of matrix A. The weight of the index is checked by normalizing $\mathrm{W}$. If the consistency is not satisfied, the original judgment matrix needs to be modified until the consistency is satisfied. Formula (3) is a consistency test formula [26].

$$
\mathrm{CI}=\frac{\lambda_{\max }-n}{n-1} .
$$

Among them, CI is the consistency index, $\lambda_{\max }$ is the largest eigenvalue of matrix $\mathrm{A}$, and $n$ is the order of judgment matrix. The formula for calculating the average random consistency index CR is

$$
\mathrm{CR}=\frac{\mathrm{CI}}{\mathrm{RI}} .
$$

When $\mathrm{CR}<0.1$, the judgment matrix satisfies consistency. RI is an average random consistency index, and its specific value varies with the order of the judgment matrix.

4.1. Accident Prevention Evaluation. According to the construction safety system based on the CPS technology [27], the corresponding indicators and evaluation system are established, as shown in Figure 9.

From Figure 9, it can be seen that the comprehensive evaluation index system consists of five parts, which are operating personal management system, monitoring early system, risk crossearly warning system, visual monitoring system, and relevant supporting system.

Table 4 is the parameter symbols set according to the main control content of each subsystem.

Taking reduction of the possibility of an accident as a standard, according to the judgment criteria of Saaty scale method, two or two indexes are compared to get their respective importance. Accordingly, the judgment matrix $A$ of the personnel management system, the judgment matrix $B$ of the monitoring and warning system, the judgment matrix $C$ of the risk crossover and warning system, the judgment matrix $D$ of the visual monitoring system, and the corresponding system judgment matrix $E$ can be obtained [28], as follows:

$$
\begin{aligned}
& A=\left[\begin{array}{cc}
1 & 3 \\
1 / 3 & 1
\end{array}\right], \\
& B=\left[\begin{array}{cccccc}
1 & 1 & 3 & 2 & 7 & 8 \\
1 & 1 & 4 & 5 & 3 & 6 \\
1 / 3 & 1 / 4 & 1 & 1 / 2 & 1 / 3 & 3 \\
1 / 2 & 1 / 5 & 2 & 1 & 3 & 5 \\
1 / 7 & 1 / 3 & 3 & 1 / 3 & 1 & 6 \\
1 / 8 & 1 / 6 & 1 / 3 & 1 / 5 & 1 / 6 & 1
\end{array}\right], \\
& C=\left[\begin{array}{cccc}
1 & 3 & 7 & 4 \\
1 / 3 & 1 & 6 & 5 \\
1 / 7 & 1 / 6 & 1 & 1 / 2 \\
1 / 4 & 1 / 5 & 2 & 1
\end{array}\right] \text {, } \\
& \begin{array}{lll}
1 & 5 & 8
\end{array} \\
& D=1 / 5 \quad 1 \quad 3 \text {, } \\
& \begin{array}{lll}
1 / 8 & 1 / 3 & 1
\end{array} \\
& E=\left[\begin{array}{ccc}
1 & 4 & 9 \\
1 / 4 & 1 & 5 \\
1 / 9 & 1 / 5 & 1
\end{array}\right] .
\end{aligned}
$$


TABLE 2: Standard table of evaluation grade.

\begin{tabular}{|c|c|c|c|c|c|}
\hline Level & 1 & 2 & 3 & 4 & 5 \\
\hline Evaluation value & $X<15$ & $15 \leqq X<40$ & $40 \leqq X<60$ & $60 \leqq X<80$ & $80 \leqq X$ \\
\hline Evaluation language & Dangerous & Severe & General & Safer & Safety \\
\hline
\end{tabular}

TABLE 3: Saaty scale method.

\begin{tabular}{lc}
\hline Meaning & Scale value \\
\hline$X_{\mathrm{m}}$ and $X_{\mathrm{n}}$ are equally important & 1 \\
$X_{\mathrm{m}}$ is slightly more important than $X_{\mathrm{n}}$ & 3 \\
$X_{\mathrm{m}}$ is obviously more important than $X_{\mathrm{n}}$ & 5 \\
$X_{\mathrm{m}}$ is more important than $X_{\mathrm{n}}$ & 7 \\
$X_{\mathrm{m}}$ is extremely important than $X_{\mathrm{n}}$ & 9 \\
$2,4,6$, and 8 are the two adjacent median values & \\
\hline
\end{tabular}

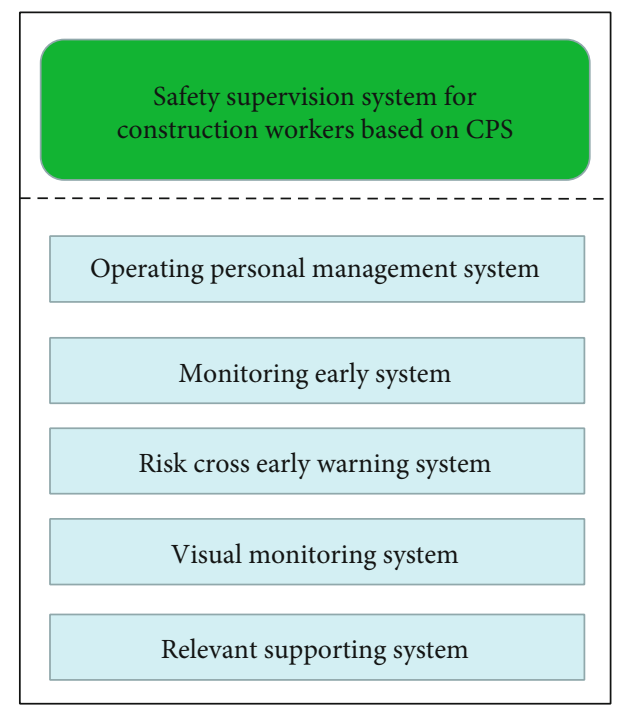

FIGURE 9: Comprehensive evaluation index system.

After calculation, the maximum eigenvalues of matrices $A, B, C, D$, and $E$ are 2.0, 6.6, 4.2, 3.04, and 3.07, respectively, and the corresponding eigenvectors of the maximum eigenvalues are $a=(0.75,0.25), \quad b=($ $0.31,0.32,0.07,0.15,0.12,0.03), c=(0.52,0.32,0.06,0.10), d=$ $(0.74,0.18,0.08)$, and $e=(0.70,0.24,0.06)$, respectively. The eigenvectors are obtained by normalization, so each element in the vector is the weight value of the corresponding factor. According to formula (4), the average randomness index CR of each judgment matrix is less than 0.1 ; that is, each judgment matrix satisfies the consistency.

The weights calculated for each index are sorted, and Table 5 is obtained.

The weights of each index are shown in a histogram. Figure 10 shows that the weights are divided into three intervals according to the size of the weights [29]. The weight in the third interval is more than 0.5 , the weight in the second interval is between 0.25 and 0.5 , and the weight in the first interval is between 0 and 0.25 .
Looking at Figure 10, there are four indicators with weights greater than 0.5 , namely, special equipment/regional access control $\left(A_{1}\right)$, human and dangerous area $\left(C_{1}\right)$, operation process supervision $\left(D_{1}\right)$, and safety training and education $\left(E_{1}\right)$. This shows that in the case of accident prevention, effective control of the four indicators in the third section is the key to prevent accidents.

Indicators with weight values in the second interval are tower crane $\left(B_{1}\right)$, foundation pit engineering $\left(B_{2}\right)$, and human and equipment $\left(C_{2}\right)$, and the weight values of these three indicators are similar, and there are intersections among the indicators. During construction, tower crane accidents accounted for the majority of all kinds of accidents. As one of the important equipment in the construction site, safety management of tower crane has become an important measure to prevent accidents.

Most of the indicators are in the first interval, but there are still some indicators with larger weights, such as active area control $\left(A_{2}\right)$, environment $\left(B_{4}\right)$, template engineering $\left(B_{5}\right)$, safety hidden danger monitoring $\left(D_{2}\right)$, and safety protection $\left(E_{2}\right)$. As a passive safety measure, safety protection can effectively protect workers in a potentially dangerous working environment and avoid accidents. The control of active area avoids construction workers entering unfamiliar environment and accidents caused by workers' wrong operation. Safety hidden danger monitoring and template engineering belong to "machine" and "environment" of humanmachine-environment, respectively. As the main object of accident injury, the people's supervision and monitoring of "machine" and "environment" can avoid accidental energy release and cause human injury.

Other weight indicators are not very different, but they also play an important role in the prevention of safety accidents. In the process of safety supervision of construction site workers, any safety measure in the construction safety system based on the CPS technology is indispensable.

\section{Conclusion}

Firstly, in view of the losses caused by frequent accidents on the construction site, the characteristics of the construction personnel and the construction site are analyzed. This paper applies the CPS technology to construction operation and constructs a safety supervision system consisting of personnel management system, risk crosswarning system, monitoring and early warning system, and remote monitoring system. According to the characteristics of the CPS technology, the perception layer perceives the scene and transmits it to the network layer in the form of data. The network layer analyzes the data through a program set in advance and feeds back the analysis to the application layer. The application 
TABLE 4: Indicators for each system.

\begin{tabular}{|c|c|c|}
\hline $\begin{array}{l}\text { System and symbolic } \\
\text { representation }\end{array}$ & & $\begin{array}{l}\text { Indicators and symbolic } \\
\text { representation }\end{array}$ \\
\hline \multirow[t]{2}{*}{$A$} & $A_{1}$ & $\begin{array}{l}\text { Special equipment/regional } \\
\text { access control }\end{array}$ \\
\hline & $A_{2}$ & Active area control \\
\hline \multirow{6}{*}{$B$} & $B_{1}$ & Tower crane \\
\hline & $B_{2}$ & Foundation pit engineering \\
\hline & $B_{3}$ & Scaffolding \\
\hline & $B_{4}$ & Environment \\
\hline & $B_{5}$ & Template engineering \\
\hline & $B_{6}$ & Structure \\
\hline \multirow{4}{*}{ C } & $C_{1}$ & Human and dangerous areas \\
\hline & $C_{2}$ & People and equipment \\
\hline & $C_{3}$ & Equipment and hazardous areas \\
\hline & $C_{4}$ & Equipment and equipment \\
\hline \multirow{3}{*}{$D$} & $D_{1}$ & Operational process supervision \\
\hline & $\mathrm{D}_{2}$ & $\begin{array}{l}\text { Safety hidden danger } \\
\text { monitoring }\end{array}$ \\
\hline & $D_{3}$ & Safety status monitoring \\
\hline \multirow{3}{*}{$E$} & $E_{1}$ & Safety training and education \\
\hline & $E_{2}$ & Safety protection \\
\hline & $E_{3}$ & Emergency system \\
\hline
\end{tabular}

TABLE 5: Weight values of indicators and their ranking.

\begin{tabular}{lccc}
\hline Target layer & $\begin{array}{c}\text { Weight } \\
\text { value }\end{array}$ & $\begin{array}{c}\text { Total } \\
\text { sort }\end{array}$ \\
\hline$A_{1}$ & Special equipment/regional access & 0.75 & 0.0317 \\
$A_{2}$ & control & 0.25 & 0.0578 \\
$B_{1}$ & Active area control & 0.311 & 0.0623 \\
$B_{2}$ & Toundation pit engineering & 0.3215 & 0.0748 \\
$B_{3}$ & $\quad$ Scaffolding & 0.0748 & 0.0768 \\
$B_{4}$ & Environment & 0.1448 & 0.1027 \\
$B_{5}$ & Template engineering & 0.1161 & 0.1161 \\
$B_{6}$ & Structure & 0.0317 & 0.1448 \\
$C_{1}$ & Human and dangerous areas & 0.5212 & 0.1863 \\
$C_{2}$ & People and equipment & 0.3183 & 0.2364 \\
$C_{3}$ & Equipment and hazardous areas & 0.0578 & 0.25 \\
$C_{4}$ & Equipment and equipment & 0.1027 & 0.311 \\
$D_{1}$ & Operational process supervision & 0.7370 & 0.3183 \\
$D_{2}$ & Safety hidden danger monitoring & 0.1863 & 0.3215 \\
$D_{3}$ & Safety status monitoring & 0.0768 & 0.5212 \\
$E_{1}$ & Safety training and education & 0.7013 & 0.7013 \\
$E_{2}$ & Safety protection & 0.2364 & 0.737 \\
$E_{3}$ & Emergency system & 0.0623 & 0.75 \\
\hline & & &
\end{tabular}

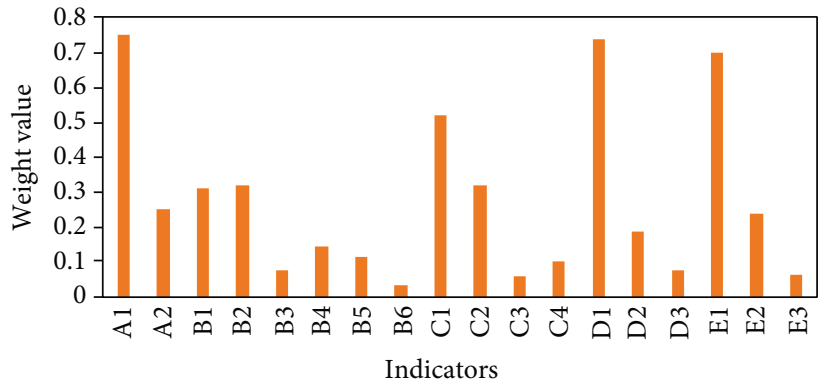

FIGURE 10: Histogram of weight values for each watch.

layer makes specific responses, such as risk warning and accident command, to reduce the losses caused by accidents.

Secondly, in this paper, the fuzzy comprehensive evaluation method is used to evaluate the performance of the system; it verifies the feasibility of the safety supervision system of construction workers based on the CPS technology and further concludes that avoiding workers' contact with dangerous areas is an important factor to reduce accidents. According to the statistics of annual construction accidents, it is known that high-altitude falling and collapse account for the majority of accidents, and by controlling human contact with dangerous areas, accidents can be effectively prevented. From the evaluation results, this method has also achieved good results and advantages. Therefore, the safety supervision system constructed in this paper will improve the level of construction safety management and reduce the incidence of accidents, which is worthy of adoption by construction enterprises.

Finally, due to the limitations of research conditions, resources, and time, some aspects need further study. In the follow-up study, more scientific research methods such as observation and experiment can be used to collect data on safety behaviors and safety results. Meanwhile, as leaders and policy makers and executors, managers of construction enterprises and staff of safety supervision departments of the government are also included in the study. The theoretical contribution of this article is to provide a new method for the field of safety management and expand the research horizon of related issues.

\section{Data Availability}

The data used to support the findings of this study are available from the corresponding author upon request.

\section{Conflicts of Interest}

The authors declare that there are no conflicts of interest regarding the publication of this paper.

\section{Acknowledgments}

This research is supported by the project of Hebei Development and Reform Commission "Research on the operation policy of Hebei Import cross-border e-commerce" of which the project no. is Z20200012. At the same time, this study is 
also supported by the research project of Shijiazhuang University of Post and Telecommunications, "the decision of Hebei province to import cross-border electricity supplier operation mode," number YB2019013.

\section{References}

[1] L. Wang and X. V. Wang, Cloud-Based "Cyber-Physical Systems in Manufacturing,", vol. 2 of Latest advancement in CPS and IoT applications, , Cham: Springer InternationalPublishing, 2018.

[2] A. Sajid, H. Abbas, and K. Saleem, "Cloud-assisted IOT-based SCADA systems security: a review of the state of the art and future challenges," IEEE Access, vol. 4, pp. 1375-1384, 2017.

[3] Y. Zhang, M. Qiu, C.-W. Tsai, M. M. Hassan, and A. Alamri, "Health-CPS: healthcare cyber-physical system assisted by cloud and big data," IEEE Systems Journal, vol. 11, no. 1, pp. 88-95, 2017.

[4] Z. B. Yang, Research on the problems and counter measures of construction safety management, vol. 5, Housing and Real Estate, 2017.

[5] X. R. Zhao, "Discussion on the role of construction engineering safety standardization construction in safety production," Metallurgical Collections, vol. 1, pp. 163-164, 2018.

[6] X. L. Song, Z. Zhang, J. P. Xu, Z. Zeng, C. Shen, and F. PeñaMora, "Bi-stakeholder conflict resolution-based layout of construction temporary facilities in large-scale construction projects," International Journal of Civil Engineering, vol. 16, no. 8, pp. 941-964, 2018.

[7] Y. Zhang, "Problems and countermeasures of building safety management in China," Theoretical Research in Urban Construction, vol. 5, no. 13, pp. 13-17, 2015.

[8] J. Liu, "Current situation and direction of construction safety management," Theoretical Research in Urban Construction, vol. 22, pp. 236-237, 2015.

[9] J. Qiu, "Talking about safety management and protection countermeasure of building construction," Real Estate Biweekly, vol. 19, pp. 319-319, 2014.

[10] I. W. H. Fung, V. W. Y. Tam, C. P. Sing, K. K. Tang, and S. O. Ogunlana, "Psychological climate in occupational safety and health: the safety awareness of construction workers in South China," International Journal of Construction Management, vol. 16, no. 4, pp. 315-325, 2016.

[11] J. Li, L. Zhang, X. Feng, K. Jia, and F. Kong, "Feature extraction and area identification of wireless channel in mobile communication," Journal of Internet Technology, vol. 20, no. 2, pp. 545-553, 2019.

[12] J. Teizer and T. Cheng, "Proximity hazard indicator for workers-on-foot near miss interactions with construction equipment and geo-referenced hazard areas," Automation in Construction, vol. 60, no. 2015, pp. 58-73, 2015.

[13] A. Yang, Y. Li, F. Kong, G. Wang, and E. Chen, "Security control redundancy allocation technology and security keys based on Internet of Things," Ieee Access, vol. 6, no. 1, pp. 50187-50196, 2018.

[14] M. Loosemore and J. Bridgeman, "Corporate volunteering in the construction industry: motivations, costs and benefits," Construction Management and Economics, vol. 2017, pp. 113, 2017.

[15] H. Fu, G. Manogaran, K. Wu, M. Cao, S. Jiang, and A. Yang, "Intelligent decision-making of online shopping behavior based on Internet of things," International Journal of Information Management, vol. 50, pp. 515-525, 2020.

[16] M. L. Whiteman, P. L. Fernández-Cabán, B. M. Phillips, F. J. Masters, J. A. Bridge, and J. R. Davis, "Multi-objective optimal design of a building envelope and structural system using cyber-physical modeling in a wind tunnel," Frontiers in Built Environment, vol. 4, pp. 13-25, 2018.

[17] O. Chieochan, A. Saokaew, and E. Boonchieng, "An integrated system of applying the use of Internet of Things, RFID and cloud computing: a case study of logistic management of Electricity Generation Authority of Thailand (EGAT) Mae Mao Lignite Coal Mining, Lampang, Thailand," in 2017 9th International Conference on Knowledge and Smart Technology (KST),, Chonburi, Thailand, February 2017.

[18] Q. Wu, X. Fan, W. Wei, and M. Wozniak, "Dynamic scheduling algorithm for delay-sensitive vehicular safety applications in cellular network," Information Technology and Control, vol. 49, no. 1, pp. 161-178, 2020.

[19] A. Yang, X. Yang, W. Wu, H. Liu, and Y. Zhuansun, "Research on feature extraction of tumor image based on convolutional neural network," IEEE Access, vol. 7, no. 1, pp. 24204-24213, 2019.

[20] M. K. Ghorabaee, M. Amiri, E. K. Zavadskas, and J. Antucheviciene, "A new hybrid fuzzy MCDM approach for evaluation of construction equipment with sustainability considerations," Archives of Civil \& Mechanical Engineering, vol. 18 , no. 1, pp. 32-49, 2018.

[21] M. Gajzler and K. Zima, "Evaluation of planned construction projects using fuzzy logic," International Journal of Civil Engineering, vol. 15, no. 4, pp. 641-652, 2017.

[22] L. Wang, H. Y. Zhang, J. Q. Wang, and L. Li, "Picture fuzzy normalized projection-based VIKOR method for the risk evaluation of construction project," Applied Soft Computing, vol. 64, pp. 216-226, 2018.

[23] W. Wei, M. Guizani, S. H. Ahmed, and C. Zhu, "Guest editorial: special section on integration of big data and artificial intelligence for Internet of Things," IEEE Transactions on Industrial Informatics, vol. 16, no. 4, pp. 2562-2565, 2020.

[24] X. Hu, W. Pedrycz, and X. Wang, "Granular fuzzy rule-based models: a study in a comprehensive evaluation and construction of fuzzy models," IEEE Transactions on Fuzzy Systems, vol. 25, no. 5, pp. 1342-1355, 2017.

[25] J. Zhao, L. Yu, and L. Li, "Construction of an evaluation and selection system of emergency treatment technology based on dynamic fuzzy GRA method for phenol spill," AIP Conference Proceedings, vol. 1839, no. 1, 2017.

[26] L. Wang and T. Haupt, "The fuzzy in evassluation of concrete structure engineering," Journal of Engineering Design and Technology, vol. 16, no. 2, pp. 327-338, 2018.

[27] A. Ardeshir and M. Mohajeri, “Assessment of safety culture among job positions in high-rise construction: a hybrid fuzzy multi criteria decision-making (FMCDM) approach," International Journal of Injury Control and Safety Promotion, vol. 25, no. 4, pp. 1-12, 2018.

[28] Y. Jin, G. Li, and H. Zhang, "Evaluation of regional rural information environment based on fuzzy method in the era of the Internet of Things," IEEE Access, vol. 6, pp. 78530-78541, 2018.

[29] W. Wei, X. Xia, M. Wozniak, X. Fan, R. Damaševičius, and Y. Li, "Multi-sink distributed power control algorithm for cyber-physical-systems in coal mine tunnels," Computer Networks, vol. 161, pp. 210-219, 2019. 